\title{
Barrier Methods for the Prevention of Infectious Diseases: Decades of Condom Research can Inform the Promotion of Face Mask Use
}

\author{
Ronald O. Valdiserri ${ }^{1}$ - David R. Holtgrave ${ }^{2}$. Seth C. Kalichman ${ }^{3}$
}

Published online: 28 August 2020

(c) Springer Science+Business Media, LLC, part of Springer Nature 2020

Let's consider two seemingly unrelated protective behaviors: using a condom to interrupt the transmission of HIV and wearing a mask to prevent the spread of SARS-CoV-2. At first blush, these two activities would seem to have very little in common. Not only do they involve distinctly different features of the human anatomy but the latter (i.e., mask wearing) is a practice typically adopted in public venues, while the former takes place in the most private of settings. Yet, on closer consideration, there are discernable similarities between these two practices. Both actions are often perceived as inconvenient or troublesome, fettering as they do, natural biologic activities. Furthermore, despite documented efficacy, the prevention effectiveness of both requires ready access to the needed gear along with the knowledge and skills of how to properly and consistently use said gear. Just as there are incorrect ways to don and doff a condom, masks, too, can be worn in a fashion that defeats their intended purpose. And finally, the uptake of both of these prevention practices can be significantly influenced by our own attitudes as well as the attitudes and practices of our peers and other, so-called, opinion leaders.

This rather metaphorical comparison is offered not as an exercise in intellectual calisthenics, but to assert that efforts to promote the consistent and proper use of face masks to prevent the spread of SARS-CoV-2 will require the same breadth of scientific underpinning that went into our national efforts to promote condom use during the first decades of the AIDS epidemic. Currently, much of the discussion surrounding mask wearing as a strategy to prevent the further spread of SARS-CoV-2 has focused on the need for mandatory regulations to enforce consistent use [1]. While we

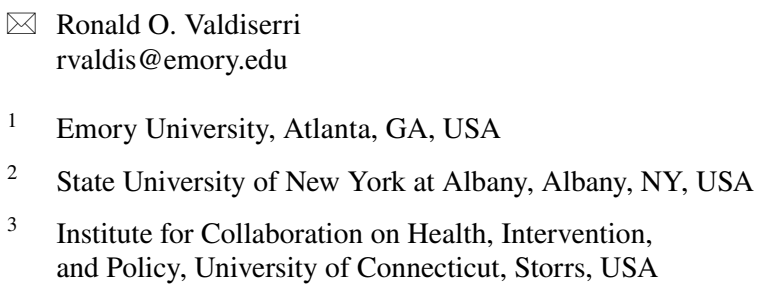

agree that structural interventions, such as policies requiring that masks be worn when entering stores or other public places, play an important role in promoting consistent mask wearing, we assert that encouraging the proper and consistent use of face masks will require a broader effort - an effort that employs a variety of science-based interventions to promote this protective behavior. Using examples from the published HIV/AIDS literature on condom use, we highlight the importance of the following steps in developing a family of strategies to promote the consistent and correct use of face masks to help prevent the spread of SARS-CoV-2:

- collecting data to understand the frequency of the prevention behavior and the variables and attitudes that influence its use;

- using multiple channels of communication to promote accurate information about the prevention behavior;

- crafting targeted interventions to promote the uptake of the prevention behavior;

- and, monitoring the uptake of the prevention behavior among specific populations and within geographic areas to assess intervention effectiveness.

\section{Collecting Data to Understand Frequency and Use}

In the earliest years of the AIDS epidemic, when effective treatments were non-existent, public health leaders focused on the importance of consistent and correct condom use as one of the primary strategies to prevent the sexual transmission of the virus. A critical component of those efforts entailed surveys and studies among key target populations to assess the frequency of using condoms and to better understand the variables and circumstances associated with their use. Collecting information from sexually active gay men [2], heterosexual men and women presenting for STD clinic services [3], women seeking contraceptive care [4], 
and women living in inner-city public housing developments [5] helped to identify potential avenues for intervention, including: improving ready access to condoms, addressing negative attitudes about condoms and their use, developing condom negotiation skills, and creating strategies to enhance partners' acceptance of condoms.

Given the age of the COVID-19 pandemic (i.e., less than 1 year old at the time of this writing), the lack of a robust literature on the variables associated with face mask usage is not altogether surprising. Gallup, an American analytics and advisory company, has been measuring US adults' use of face masks since April 2020; their July 2020 assessment indicates than less than half (44\%) of US adults report "always" wearing a mask outside their home [6]. This same assessment revealed that women, persons identifying as Democrats and those living in the Northeastern U.S. were most likely to always use a mask in public. Variables influencing the use of face masks are likely to change over time-indeed, the U.S. President's recent endorsement of face masks was associated with a significant increase in their support among members of his political party [7]. Therefore, it will be necessary to continually assess the frequency of this protective behavior among key target populations and in areas prone to community spread of SARS-CoV-2. Furthermore, ongoing assessments will need to become more finely tuned in order to unravel the demographic, attitudinal and situational factors associated with face mask usage. As is evident when one reviews the formative literature on condom use to prevent HIV, such nuanced information will be necessary in order to inform intervention development.

\section{Promoting Accurate Information Through Multiple Channels}

As acknowledged in print [8] and broadcast media [9], many Americans are confused about current recommendations for mask wearing to prevent the spread of SARS-CoV-2. In part, this confusion derives from changing recommendations about mask use, both in the U.S. and elsewhere $[10,11]$. Initially, facial coverings were not recommended for the general public. Now, the U.S. Centers for Disease Control and Prevention (CDC) recommends that "people wear cloth face coverings in public settings and when around people who don't live in your household, especially when other social distancing measures are difficult to maintain" [12]. In large part, these temporal variations in recommended mask guidance stem from the expanding knowledge base related to both SARS-CoV-2 transmission as well as the efficacy of face masks in preventing viral transmission. Although legitimate questions remain about the overall prevention effectiveness of mask wearing at a population level-especially when considering its impact on other prevention strategies such as social distancing [13]—emerging evidence provides support for policies calling for masking in public as a means of preventing the spread of SARS-CoV-2 [14-16].

In a scenario like the COVID-19 pandemic, where epidemiologic trends are emerging at a rapid pace and new scientific findings are reported daily, accurate, unambiguous and timely information, delivered through multiple channels, is critical. Here, too, our nation's response to the AIDS epidemic provides an exemplar. Granted, the absence of both the world wide web and our now nearly ubiquitous social media made for a very different communication landscape in the first decade of the U.S. AIDS epidemic. However, responding to our, then, novel epidemic, the federal government invested in a variety of strategies to spread accurate information about AIDS. A National AIDS Hotline was established in February 1983 and provided toll-free, live information specialists to answer questions about AIDS twenty-four hours a day, seven days a week [17]. In 1987, CDC implemented "America Responds to AIDS"- - described as both a public information and social marketing campaign, designed to disseminate "accurate and timely information via multiple communication channels and vehicles" [18]. And in 1988, CDC mailed a seven page informational booklet, "Understanding AIDS," to every household in the United States; special mailings were made to reach the military, Americans assigned abroad, prisoners, persons in juvenile detention facilities and those living in homeless shelters [19]. Among the topics addressed in the booklet were: "How Do you Get AIDS?"; "What Behavior Puts You at Risk?"; and "What is All the Talk about Condoms?". The section on condoms stated unambiguously that "condoms are the best preventive measure against AIDS besides not having sex" and provided basic information about proper condom use [20].

None of the vehicles developed to disseminate accurate information about AIDS and the practices needed to prevent its transmission-like consistent and correct condom useemerged overnight. But it is worth noting that in the absence of a vaccine or a curative treatment for HIV infection, the federal government made substantial, sustained investments into the development of long-term strategies to ensure that both the general public as well as high-risk populations could access up-to-date information about the epidemic, and steps to prevent viral transmission, in a timely and userfriendly manner. We have not yet seen similar investments at the federal level as pertains to information dissemination about SARS-CoV-2 and the COVID-19 pandemic.

\section{Crafting Targeted Interventions to Promote the Prevention Behavior}

When it comes to condom use, facial masking or any other prevention practice, accurate information is important to dispel myths and to promote awareness. But by 
itself, knowledge doesn't necessarily translate into the desired behavior change. In addition to other individuallevel factors such as attitudes about the practice and one's perceived ability to adopt the behavior, external factors, including peer norms and the various "costs" of adopting the desired prevention behavior, can strongly influence our actions. As such, it is understandable that CDC recently noted that public health messages targeting audiences not wearing cloth face coverings should "reinforce positive attitudes, perceived norms, personal agency, and the physical health benefits of obtaining and wearing cloth face coverings" [21]. Therefore, in addition to providing accurate information about face masks for SARS-CoV-2 prevention, it will also be necessary to develop and test specific interventions promoting their consistent and correct use.

Again, we can draw comparisons to related public health efforts to prevent HIV through the promotion of consistent condom use. To achieve this desired outcome, the federal government supported a variety of research studies to inform the scientific bases for sound condom promotion programs. These efforts documented a number of key factors that are important influencers of condom use, including: sexual communication skills [22, 23]; condom use skills [24]; endorsement by popular opinion leaders [25]; community-wide norms and practices [26]; and the availability of or accessibility to condoms [27]. Although these examples represent only a fraction of the research that has been and continues to be published in this domain, they serve to underscore the critical role that behavioral science plays in understanding and promoting the adoption of any prevention practice. Public health interventions to promote the use of face masks as a strategy to prevent SARS-CoV-2 will, likewise, require a sound science base.

Drawing the analogy to HIV prevention research even further, interventions cannot be "one size fits all." Interventions and messages promoting face mask use among young adults who underestimate their risk of SARS-CoV-2 acquisition and the subsequent consequences of COVID19 disease will likely differ from efforts aimed at populations that are at disproportionate risk for SARS-CoV-2 infection because of underlying disease conditions and/ or ambient social factors. As we learned during the HIV/ AIDS epidemic, prevention interventions must be tailored to the circumstances and needs of their specific audiences. Therefore, even as we continue to invest in vaccine development and other biomedical solutions to the pandemic, responding to the current threat of SARS-CoV-2 and preparing for future pandemics of respiratory pathogens, requires that we support behavioral science research to inform the development of other prevention interventions, including consistent face mask use.

\section{Monitoring the Uptake of the Prevention Behavior}

Like all human behaviors, the frequency of a particular prevention practice can change over time, increasing in some population segments while decreasing in others. These variations may result from a host of influences ranging from alterations in individual risk perception to shifts in the socio-economic milieu. Consequently, it becomes necessary to monitor trends in prevention behaviors so as to determine the continued relevance and effectiveness of prevention strategies. In the HIV realm, data from the National HIV Behavioral Surveillance System [28] and other population-based longitudinal surveys $[29,30]$ have been used to monitor trends in condom use and other prevention practices, so as to inform the development of prevention policy and to identify needed modifications to existing prevention messages and strategies.

Similar longitudinal surveys will be necessary to understand changes in face mask use and other practices to prevent the transmission of SARS-CoV-2. Nor can we rely solely on public opinion polls to provide this information. Instead, we need investment at the federal level to provide states and localities with the resources they require to develop sound behavioral surveillance systems, allowing them to collect complete and valid data in a timely manner [31]. Evaluating changes in face mask use across time and within various population segments will allow for rapid adjustments to SARS-CoV-2 messaging and, if called for, the development of new and enhanced interventions to promote mask use.

\section{Conclusion}

As some readers may be aware, this is not the first instance of our suggesting that America's decades-long experience with the HIV/AIDS pandemic can provide valuable insights into how best to respond to the epidemic spread of SARS-COV-2 [32]. Despite substantial differences between the two viruses and the diseases that they cause, reviewing the national response to the HIV/AIDS epidemic makes a strong case for the importance of developing comprehensive, well-funded and long-term strategies when faced with the threat of an expanding epidemic. As demonstrated by the select examples provided in this commentary, the federal government's efforts to promote condom use to prevent the sexual transmission of HIV required sustained investments into the development of surveillance systems to monitor the behavior, behavioral research studies to identify targets for intervention, 
communication channels to disseminate accurate information and community-based programs to promote "safer sex" and to provide ready access to condoms and other prevention services. These systems did not develop immediately nor were they solely the province of federal planners; leaders from academia, state and local government and advocates from affected communities had a substantial role in creating and shaping these efforts [33]. Nonetheless, without the necessary resources and support at the federal level, it is unlikely that they would have developed in a consistent and comprehensive manner across the United States.

Likewise, any serious effort to promote the use of face masks as a strategy to prevent the transmission of SARSCoV-2 must extend beyond issuing mandates and will require strong federal backing as outlined above. Making state and local governments solely responsible for addressing this need-especially at a time of looming budget shortfalls [34] - is sure to result in an inadequate and uneven prevention response. Certainly, the immediate and immense economic [35] and social issues (when and how best to re-open schools, for example) engendered by this pandemic can often overshadow concerns that are seemingly less consequential, such as how to promote prevention practices like consistent face mask use. And at a time when so much of the national focus is, understandably, centered on the development of a safe and effective SARS-CoV-2 vaccine, this concern may appear to be of secondary importance. To that point, the National Institutes of Health's recent "NIH-Wide Strategic Plan for COVID-19 Research" states that "NIH will support studies on preventive treatments, behavioral and community prevention practices," but makes no specific mention of funding behavioral research studies to help us better understand the variables that influence the consistent use of face masks in community settings [36].

Let's be clear; face masks are no panacea for ending the COVID-19 pandemic. But in the same way that condoms played a significant role in HIV prevention-especially in the days before the availability of pre-exposure prophylaxis for HIV and effective treatments that can effectively interrupt sexual transmission of the virus-consistent and correct face mask use can contribute to interrupting the spread of SARS-CoV-2. But this is unlikely to happen without a national commitment to the development and support of comprehensive, scientifically based prevention strategies that address all relevant avenues for interrupting the spread of SARS-CoV-2.

\section{References}

1. Fairchild AL, Healton C, Galea S. A National Mandatory Order to Wear a Mask would keep People from becoming 'Walking
Weapons.” STAT. 2020. https://www.statnews.com/2020/07/15/ national-mandatory-mask-order-prevent-walking-weapons/

2. Valdiserri RO, Lyter D, Leviton LC, et al. Variables influencing condom use in a cohort of gay and bisexual men. Am J Public Health. 1988;78(7):801-5.

3. Centers for Disease Control. Heterosexual behaviors and factors that influence condom use among patients attending a sexually transmitted disease clinic-San Francisco. Morb Mortal Weekly Rep. 1990;39(39):685-9.

4. Valdiserri RO, Arena VC, Proctor D, Bonati FA. The relationship between women's attitudes about condoms and their use: implications for condom promotion programs. Am J Public Health. 1989;79(4):499-501.

5. Heckman TG, Sikkema KJ, Kelly JA, et al. Predictors of condom use and human immunodeficiency virus test seeking among women living in inner-city public housing developments. Sex Trans Dis. 1996;23(5):357-65.

6. Brenan M. Americans' Face Mask Usage Varies Greatly by Demographics. GALLUP. 2020 Jul 13. https://www.news.gallup.com/ poll/315590/americans-face-mask-usage-varies-greatly-demog rpahics.aspx

7. Grzeszczak J. Republican Support for Wearing Masks Leaps to 58\% After Trump Wears One in Public for First Time. Newsweek. 2020. https://www.newsweek.com/republican-support-wearingmasks-leaps-58-after-trump-wears-one-public-first-time-1520043

8. Wirecutter Staff. Why we've taken down our outdated coronavirus mask coverage. New York Times. 2020. https://www.nytim es.com/wirecutter/blog/coronavirus-face-masks-coverage/

9. Breslow J. Fauci: Mixed Messaging on Masks Set U.S. Public Health Response Back. 2020. https://www.npr.org/sections/healt h-shots/2020/07/01/886299190/it-does-not-have-to-be-100-000cases-a-day-fauci-urges-U-S-to-follow-guidelines

10. Missoni E, Armocida B, Formenti B. Face Masks For All And All For Face Masks in the COVID-19 pandemic: community level production to face the global shortage and shorten the epidemic. Disaster Med Public Health Prep. 2020;24:1-5. https://doi. org/10.1017/dmp.2020.207.

11. Cohen J. The Complex Global Evolution of Coronavirus Mask Rules. Forbes. 2020 Jul 12. https://www.forbes.com/sites/joshu acohen/2020/07/12/the-complex-global-evolution-of--coronaviru s-mask-rules/\#5fdeb7f5428d

12. Centers for Disease Control and Prevention. Considerations for Wearing Cloth Face Coverings. 2020 Jul 16. https://cdc.govco ronavirus/2019-ncov/prevent-getting-sick/cloth-face-cover-guida nce.html

13. Osterholm MT. My Views on Cloth Face Coverings for the Public for Preventing COVID-19. 2020 Jul 22. https://cidrap.umn.edu/ news-perspective/2020/07/commentary-my-views-cloth-facecoverings-public-preventing-covid-19

14. Ma QX, Shan H, Zhang HL, Li GM, Yang RM, Chen JM. Potential utilities of mask-wearing and instant hand hygiene for fighting SARS-CoV-2. J Med Virol. 2020. https://doi.org/10.1002/ jmv. 25805 .

15. Lyu W, Wehby GL. Community use of face masks and COVID19: evidence from a natural experiment of state mandates in the US. Health Aff. 2020;39(8):1-7.

16. Hendrix JM, Walde C, Findley K, Trotman R. Absence of apparent transmission of SARS-CoV-2 from two stylists after exposure at a hair salon with a universal face covering policy-Springfield, Missouri, May 2020. Morb Mortal Wkly Rep. 2020;69(28):930-2.

17. Waller RR, Lisella LW. National AIDS hotline: HIV and AIDS information service through a toll-free telephone system. Public Health Rep. 1991;106(6):628-34.

18. Woods DR, Davis D, Westover BJ. "America responds to AIDS": its content, development, process and outcome. Public Health Rep. 1991;106(6):616-22. 
19. Davis D. "Understanding AIDS"-The National AIDS Mailer. Public Health Rep. 1991;106(6):656-62.

20. U.S. Department of Health and Human Services. Understanding AIDS. HHS Publication No. (CDC) HHS-88-8404. 1988. https:// stacks.cdc.gov/view/cdc/6927

21. Fisher KA, Barile JP, Guerin RJ, et al. Factors associated with cloth face covering use among adults during the COVID-19 pandemic-United States, April and May 2020. Morb Mortal Weekly Rep. 2020;69(28):933-7.

22. Catania JA, Coates TJ, Kegeles S, et al. Condom use in multi-ethnic neighborhoods of san francisco: the population-based AMEN (AIDS in multi-ethnic neighborhoods) study. Am J Public Health. 1992;82(2):284-7.

23. Valdiserri RO, Lyter DW, Leviton LC, et al. AIDS prevention in homosexual and bisexual men: results of a randomized trial evaluating two risk reduction interventions. AIDS. 1989;3(1):21-6.

24. DiClemente RJ, Wingood GM. A randomized controlled trial of an HIV sexual risk-reduction intervention for young AfricanAmerican women. JAMA. 1995;274(16):1271-6.

25. Kelly JA, St. Lawrence JS, Stevenson Y, et al. Community AIDS/ HIV risk reduction: the effects of endorsements by popular people in three cities. Am J Public Health. 1992;82(11):1483-9.

26. CDC Aids Community Demonstration Projects Research Group. Community-level HIV intervention in 5 cities: final outcome data from the CDC AIDS community demonstration projects. Am J Public Health. 1999;89(3):336-45.

27. Charania MR, Crepaz N, Guenther-Gray C, et al. Efficacy of structural-level condom distribution interventions: a meta-analysis of US and International Studies, 1998-2007. AIDS Behav. 2011;15(7):1283-97.

28. Wejnert C, Raymond HF, Robbins T, et al. Achieving Greater HIV prevention impact through CDC's national HIV behavioral surveillance system. J Acquir Immune Defic Syndr. 2017;75(Suppl 3):S249-S252252.
29. Copen CE. Condom Use During Sexual Intercourse among Women and Men aged 15-44 in the United States: 2011-2015 National Survey of Family Growth. Natl Health Stat Rep. 2017 Aug 10: \# 105.

30. Harper CR, Steiner RJ, Lowry R, Hustetler S, Dittus PJ. Variability in condom use trends by sexual risk behaviors: findings from the 2003-2015 National Youth Risk Behavior Surveys. Sex Trans Dis. 2018;45(6):400-5.

31. Azofeifa A, Stroup DF, Lyerla R, et al. Evaluating behavioral health surveillance systems. Prev Chronic Dis. 2018;15:170459. https://doi.org/10.5888/pcd15.170459.

32. Valdiserri RO, Holtgrave DR. Responding to Pandemics: what we've learned from HIV/AIDS. AIDS Behav. 2020;24(7):1980-2.

33. Valdiserri RO, Holtgrave DR. Ending HIV in America: Not Without the Power of Community. AIDS Behav. 2019;23(11):2899-903.

34. McNichol E, Leachman M. States Continue to Face Large Shortfalls Due to COVID-19 Effects. Center on Budget and Policy Priorities. $2020 \mathrm{Jul} \mathrm{7.} \mathrm{https//www.cbpp.org/sites/default/files/atoms}$ /6-15-20sfp.pdf

35. Miller RS, Labonte M. COVID-19: U.S. Economic Effects. Congressional Research Service. 2020 May 13. https://www.crsreports .congress.gov/product/pdf/IN/IN11388

36. National Institutes of Health. NIH-Wide Strategic Plan for COVID-19 Research. 2020 Jul. https://www.nih.gov/sites/defau lt/files/research-training/initiatives/covid-19-strategic-plan/coron avirus-strategic-plan-20200713.pdf

Publisher's Note Springer Nature remains neutral with regard to jurisdictional claims in published maps and institutional affiliations. 